Boise State University

ScholarWorks

Counselor Education Faculty Publications and

Presentations

Department of Counselor Education

7-1-2009

\title{
An Interview with Alan J. Hovestadt: AAMFT Past President and Long-Time Marriage and Family Counselor Educator
}

Gerald A. Juhnke

University of Texas at San Antonio

Michael F. Sunich

Troy University

Kenneth Coll

Boise State University

Maritza Lebron-Striker

University of Texas at San Antonio 


\title{
An Interview With Alan J. Hovestadt: AAMFT Past President and Long-Time Marriage and Family Counselor Educator
}

\author{
Gerald A. Juhnke \\ The University of Texas at San Antonio \\ Michael F. Sunich \\ Troy University \\ Kenneth M. Coll \\ Boise State University \\ Maritza Lebron-Striker \\ The University of Texas as San Antonio
}

\begin{abstract}
Alan J. Hovestadt, EdD, is the immediate past president of the 24,000 member American Association for Marriage and Family Therapy (AAMFT) and a long-time IAMFC member who served as an IAMFC founding board member when ACA first granted IAMFC divisional status. Recently, Dr. Hovestadt was one of seven recipients of the prestigious American Counseling Association's Presidential Award and was honored at the 2008 ACA Conference in Honolulu, Hawaii. Given Dr. Hovestadt's prominence within both AAMFT and IAMFC and his long-time marriage and family counselor educator identity, the authors' believed that an interview with Dr. Hovestadt would be of significant interest to The Family Journal readerships. Thus, Dr. Hovestadt graciously participated in an interview with Drs. Ken Coll, Michael Sunich, and Gerald Juhnke on November 20, 2007. In the interview below, Dr. Hovestadt responds to questions related to his (a) AAMFT Presidency experiences and accomplishments, (b) perceptions related to professionals aligning themselves either with AAMFT or IAMFC, (c) thoughts related to pressing legislative concerns that would be of specific interest to IAMFC members and The Family Journal readership, (d) perceptions related to marriage and family training changes, and (e) advice for those seeing to become counselor educators with specialization in couples, marriage, and family counseling.
\end{abstract}

Keywords: interview; marriage and family therapy; counselor education; legislative concerns

Authors' Note: Correspondence concerning this review should be addressed to Gerald A. Juhnke, The University of Texas at San Antonio, 501 West Durango, San Antonio, TX 78207-4415; e-mail:gajuhnkemi@yahoo.com.

Dr. Alan J. Hovestadt is the immediate past president of the 24,000 member American Association for Marriage and Family Therapy (AAMFT). He received his doctor of education degree from Northern Illinois University's Department of Counseling and Adult and Higher Education in 1973 and served as Counselor Education Faculty member at Texas A \& M University in Commerce (TA\&M-Commerce) Texas from 1973 to 1985. From 1975 to 1985, Dr. Hovestadt directed the department's marriage and family program. This doctoral program was the first Commission on Accreditation for Marriage and Family Therapy Education (COAMFTE) accredited doctoral program in the Southwestern United States. In 1985, he left Texas A \& M University in Commerce to assume the post of department chair and professor in the department of counselor education and counseling psychology at Western Michigan University. Dr. Hovestadt has been the recipient of multiple AAMFT and IAMFC awards, including the IAMFC Distinguished Training and Mentor Award. He is an approved AAMFT clinical supervisor, an active consultant to mental health agencies, and has an independent marriage and family practice. Dr. Hovestadt participated in the following interview with Drs. Ken Coll, Michael Sunich, and Gerald Juhnke on November 20, 2007.

Juhnke: Alan, your AAMFT Presidency had to be one of the major highlights of your distinguished professional career. Would you mind telling us a little about your AAMFT Presidency? 
Hovestadt: The AAMFT Presidency certainly was a significant highlight and something that I thoroughly enjoyed, Jerry.** Although there are times within all of our professional lives' where we can positively impact our profession via the committees we serve or the positions we are appointed, being afforded the opportunity to serve as AAMFT President was quite different and very exciting. As you know the AAMFT President Post constitutes a 5-year term. The first 2 years are served as president-elect, followed by 2 years as president and a final year as past president. I served as president elect during 2003 and 2004, president in 2005 and 2006, and past president for 2007. Serving the profession as the "point person" for those 5 years was exhilarating. During that time, I experienced the profession in a way that brought about my enhanced understanding of the profession's "macro" diversity. In other words, I gained a greater understanding of the diversity among marriage and family therapists who provide clinical interventions, educational services, advocacy, and research ... all working in a way to help the diverse client couples, marriages, and families that we serve.

Sunich: During your presidency, what were the one or two major accomplishments you felt most contributed to the association?

Hovestadt: Well that's a really good question. Although there were many accomplishments, I think the two most important accomplishments of long-term value were the updating of the AAMFT strategic plan and revision of several of our governance policies.

Sunich: Let's go back to the strategic plan for a moment, would you talk about that?

Hovestadt: Sure, in 1998, the AAMFT adopted a strategic plan that had approximately 36 goals and subobjectives. In 2004, the association conducted an extensive member survey and analysis of background material on broad trends and themes affecting members and the wider communities that they work. After reviewing the data and conducting analyses of the trends, the board agreed to work toward developing a strategic plan that had much greater focus. For me, the key to successful outcome was sharpening the strategic plan's focus. Ultimately, the new strategic plan had only three goals and seven subobjectives. As family therapists and counselors, we are taught to help clients establish meaningful, realistic, and attainable goals. As president, I believed it would be far better to establish these same types of goals rather than chasing a nearly infinite number of dreams that might never come to fruition.

Coll: How did you work with AAMFT members related to the plan and how was the final strategic plan distributed to the AAMFT membership?

Hovestadt: We involved AAMFT division leaders across the United States and Canada, prior to and during the strategic plan drafting process. During the summer of 2005, we held a strategic planning workshop in Santa Rosa, California. In addition to participation of the full board of directors, we included several prominent academics, students, regulatory experts, researchers, and policy thinkers who brought tremendous diversity to the dialog. After this meeting, a draft strategic plan was shared with all AAMFT divisions and scrutinized during the fall 2005 annual conference in Kansas City. When finally adopted in December of 2005, the board had received feedback from hundreds of members. I am very proud of this accomplishment as it was devised among the leadership and transformed at the grass roots level. All AAMFT members were actively encouraged to participate in the process. This insured that the final strategic plan would be one that ushers AAMFT and the entire profession into the forefront of mental health leadership.

Juhnke: This is an incredible feat. How did you motivate so many people to come together to be a part of that strategic planning process?

Hovestadt: I think that the key issue was that all stakeholders wanted the association and profession to succeed. As with IAMFC and ACA, AAMFT has many dedicated members who are truly committed to the profession and their professional organization. Frankly, it was amazing to me that there were so many people who truly cared and believed in the strategic planning process. It was this core group who were willing to actively participate.

Sunich: The second major accomplishment was what again? 
Hovestadt: A second major accomplishment was the revision of several governing policies. If I might, I would like to briefly share a few thoughts about my personal orientation toward governing. AAMFT governance is founded on knowledge-based planning versus implementation of policies. Professional mental health associations are comprised of groups of people who voluntarily come together to solve common problems, meet common needs, and accomplish common goals. As an elected group of volunteers, the board sets goals, generates vision, and establishes policy directives. In an increasingly complex work environment, professional mental health associations must constantly examine their processes for getting association business accomplished. Periodically, governance policies need to be updated. This insures that the association is nimble and can accommodate the constant changes we face in the mental health care marketplace and the profession. For example, being from Michigan, I am quite familiar with the automotive industry. Despite changes occurring within the economy and from foreign competition, the big three automakers failed to adapt to new economic realities. When they finally realized the competitive threat from foreign based auto manufacturers, they attempted change. Regretfully, they were not nimble enough to create the necessary outcomes to keep the market share they at one time commanded. Who would have anticipated in the 1960ís and 1970ís that Toyota, Mazda, or Honda would ever become major market competitors. My guess is few if any. Marriage and family therapists and counselors must understand that simply conducting excellent mental health services is not going to guarantee our position in the mental health marketplace or workforce. We could be the most cost-effective providers within the marketplace yet still risk being eclipsed by the aggressive and not always fair legislative lobbying of other major mental health professions that have significantly deeper pockets. Therefore, our governing policies need to be efficient, relevant, focused, and precise. When professionals decide to pay membership dues to professional associations such as AAMFT, ACA and IAMFC members must perceive a value proposition that says their membership dollars are creating opportunities to be viable in the mental health delivery system throughout their lifecycle of work.

Juhnke: That makes sense, Alan.

Hovestadt: Certainly ... who would pay dues to an organization that was not positioning their membership for continued successful existence? No one I know. Thus, the revision of these governing policies was vitally important not only to the association but for the membership as well.

Coll: How long had it been since the AAMFT changed these policies? Can you talk about one major policy change?

Hovestadt: There had been some minor changes to our governance policies in the past decade, but we had not addressed several recent concerns. One major change expanded the transparency and openness of the selection and election process of commissioners for service on the AAMFT Commission on Accreditation for Marriage and Family Therapy Education (COAMFTE).

Juhnke: Can you tell us what that change in the commissioner selection/election process was?

Hovestadt: To rectify this aforementioned problem, a bylaw change was approved by the AAMFT membership in 2005. The bylaw change and revised board enacted governance policies enhanced the openness of the process of selecting and electing new commissioners. Under the old policies, the Commission utilized a self-selection process whereby current commissioners and a subgroup within that commission selected the next Commissioners. Certainly, 25 or 30 years ago, when the association was smaller and the number of AAMFT accredited programs was also limited, the process was functional and served the association well. However, the association has significantly grown and the numbers of COAMFTE accredited programs have greatly increased. We believed enfranchising accredited program directors and site visitors as commission candidate electors would enhance the selection process and bring new vision and energy to the Commission. The AAMFT Elections Council, an elected body itself, solicits nominees and decides who will be on the ballot as a candidate for commission membership.

Coll: Sounds like a very positive move.

Hovestadt: We think it was. The clinical membership believed this as well. Their belief was evident by their overwhelmingly support of the bylaw change enabling the new selection process. This change is important and relevant in maintaining a climate of fairness, openness, and inclusion.

Sunich: What is the size of the current AAMFT membership? 
Hovestadt: AAMFT has over 24,000 members. This number has been quite stable for the past several years. On a day-to-day basis, the actual number lies somewhere in the 24,000 to 25,000. The AAMFT has a Clinical Member retention rate in excess of $95 \%$ suggesting that members perceive long-term value in their membership.

Juhnke: That is impressive, Alan. What do you attribute that solid retention membership rate to?

Hovestadt: Well, there are a couple of reasons. Of current members, $66 \%$ hold master's degrees and $34 \%$ hold doctorates. Approximately, $85 \%$ of AAMFT members hold marriage and family licenses and that percentage seems to be increasing each year. I believe that professionals who join AAMFT increasingly expect and believe that this association reflects and represents their professional identity as marriage and family therapists. Second, I believe that marriage and family therapists join and retain membership due to the perception that their professional livelihoods are positively affected by the work of AAMFT and its divisions do on their behalf.

Sunich: As AAMFT President, how did you balance your roles and allegiance as both a counselor educator and marriage and family therapy educator and long-term IAMFC/ACA and AAMFT member?

Hovestadt: Over the past 40 years, I have been fortunate to have many treasured friends and trusted colleagues in ACA, IAMFC, and ACES. I have chosen to maintain memberships in ACA, IAMFC, ACES, APA, and its Division 17 (Counseling Psychology) in addition to my AAMFT membership, because these professional organizations have complemented and supported several aspects of my professional career as a university professor at Texas A \& $\mathrm{M}$ Commerce and Western Michigan University. During the greatest part of my academic and professional association leadership career, I have experienced a great deal of synergy in having multiple professional association memberships. Each membership has benefited my teaching, research, and writing. Without a doubt, these multiple memberships broadened my perspectives and knowledge about every aspect of my career. On the other hand, tensions have arisen from time to time as a result of my multiple professional memberships and association leadership activities. One has only to recall that beginning in the 1970s, both ACA and AAMFT sought professional legitimacy and recognition through attainment of licensure from state legislatures. Tension escalated in the late 1970ís when a group of ACA leaders publicly declared, in an ACA publication, that MFT existed only as a sub set of counseling skills and that it should be regulated only as part of LPC licensure. Obviously, this created conflict for the AAMFT which was seeking separate independent licensure for their members who embraced MFT as a primary professional identity. I think many people in IAMFC and ACA like me believed that MFT/C concurrently existed as an area of professional interest and practice for mental health care providers such as professional counselors and social workers as well as a distinct profession with its own professional identity. In an effort to expand understanding of the dual nature of MFT/C, former ACA President Sam Gladding and Barbara Okun coedited in 1983 an ACES and ERIC monograph on MFT training in Counselor Education. The chapter coauthored by David L. Fenell, Fred P. Peircy, and myself attempted explain a model of MFT education that would embrace MFT/C as collaborative and complementary to the training of clinical mental health counselors and future counselor educators. Now in 2008, most of the perceived and real issues that created tension between ACA, IAMFC, and the AAMFT have been resolved. For example, nearly all states offer independent LPC and MFT licenses. ACA and

AAMFT are recognized as independent professions by most federal agencies and both have successful accrediting bodies. More recently, ACA and AAMFT have collaborated on legislative proposals to recognize LPCs and LMFTs as Medicare approved nonmedical mental health care providers. In a very positive change of positions, the ACA Governing Council voted a new position statement dated October 28, 2007 indicating that "... the American Counseling Association recognizes marital/marriage and family therapy as a separate and distinct licensed profession." My hope is that we'll see even more opportunities for professional counselors and MFTs to collaborate and support one another.

Coll: Dr. Hovestadt, can you get back to the issue of trying to balance your work and family life with a five year commitment of extensive work and travel for AAMFT?

Hovestadt: Attempting to accomplish the responsibilities of being both a full time educator and serving as AAMFT President were challenging yet extremely rewarding. As I look back on the previous 5 years, I am aware that there were many weeks when I was functioning on overload. On weeks that I would travel I would often work 12 or more hours a day at my university. Then, for example, I would travel to AAMFT-related meetings. Typically, this occurred on Thursday afternoons. And, we conducted AAMFT meetings all day Fridays and Saturdays. Sundays, I 
would return to Kalamazoo. Fortunately, most of my travel involved meetings with people I enjoyed, respected, and liked. Concomitantly, much of the information I learned from these AAMFT-related meetings related to my work as a professor. I have to say on the home front that Kristin, my wife, was wonderfully understanding and accommodating with my busy schedule and long hours. Further our three children, their spouses, and families were as understanding and supportive as one could possibly hope.

Juhnke: Most marriage and family professionals understand that IAMFC and AAMFT are two separate organizations. How do you respond to professionals who believe one either has to have a single allegiance to either IAMFC or AAMFT?

Hovestadt: They are indeed separate organizations. However, for the most part, they are not competing in terms of their respective missions. Generally, AAMFT's membership leans toward those who wish to be licensed as marriage and family therapists. The majority of IAMFC members desire to be licensed as professional counselors. Interestingly, there have been a number of IAMFC and AAMFT members, who have had significant involvement in both organizations. AAMFT exists basically to advance the professional interests of people who primarily identify themselves as marital and family therapists. AAMFT members expect a full complement of services and benefits provided by a large professional organization with a multimillion dollar budget. Contrastingly, IAMFC seeks to promote couples and family counseling excellence on a national and international basis. Most IAMFC members view MFC as an interest and or practice area within their professional counselor identity, whereas the majority of AAMFT members view MFT as a comprehensive and independent mental health profession.

IAMFC serves a very important role for members who embrace family therapy or family counseling as a practice area within the much broader profession of counseling. While some of my colleagues believe that one professional society can and will meet all their professional needs, I know many people in the fields of counselor education, counseling psychology, and family therapy that are members of multiple mental health care organizations. My guess is that these professionals wish to maintain multiple marriage and family professional memberships as a means to maintain and enhance their clinical and scholarly knowledge. For example, I have always thoroughly enjoyed reading professional journals. The IAMFC Family Journal is exceptional and so is AAMFT's Journal of Marriage and Family Therapy. Both organizations are active in serving their memberships and both are committed to insuring that professional mental health issues pertaining to couples, marriages, and families are appropriately addressed. Everyone benefits when multiple associations work to address the mental health needs of our clients. It is my firm conviction that being an excellent marriage and family treatment provider means gathering as many perspectives as possible. Multiple memberships suggest that one is truly attempting to gain relevant information and knowledge to better oneself. Interestingly, several ACA and IAMFC presidents are or have been AAMFT Clinical Members. For example, ACA President, Dr. Brian Canfield, is a long-standing AAMFT member. Prior to his election as the 2007ñ2008 ACA president, Dr. Canfield served as IAMFC president.

Juhnke: Given your national leadership experience with the largest marriage and family professional organization in the world, are there any professional or legislative issues that loom on the horizon that the Family Journal readership should be aware?

Hovestadt: I think one of the continuing areas of interest and collaboration for both ACA/IAMFC and AAMFT is gaining federal recognition of professional counselors and MFT's as mental health care providers in Medicare legislation. This requires amending the Medicare law in the context of enormous budget deficits run by the federal government. Having recent success in the House of Representatives in 2007, we will need to go to the Senate this year and make our best case. The implications for the inclusion of Professional Counselors and MFT's in Medicare are huge since this legislation influences all other state and private insurance entities and companies throughout the United States.

Sunich: Al, you have been active in family counseling for a long time, how has the profession changed since you began?

Hovestadt: I think one of the most obvious changes is that there is increasing emphasis by third-party payers and consumers to understand what benefits MFTs and MFCs bring to the behavioral mental health care system. We are making real progress in terms of effectiveness and outcome research. My sense is that future treatment protocols will increasingly be influenced by the evidenced-based practices. AAMFT is in the process of planning a new 
edition of MFT outcome and effectiveness research. So much of what we did 40 and 50 years ago was based on our clinical observations and impressions. Of course that certainly doesn't mean we should automatically dismiss such treatment. But, on the other hand, we must have greater evidence that couples, marriage, and family interventions are effective. If we cannot or refuse to provide such evidence, our services will be cast as unreimbursable.

Juhnke: Al, can you talk a little about your doctoral education in counseling and family therapy at Northern Illinois University in the early 1970ís?

Hovestadt: As a doctoral student at Northern Illinois University, I was very fortunate to have two exceptional marriage and family professors. Drs. Donald Murphy and Earle Goodman were professors in family sciences and family studies. I was able to enroll in each of their courses ... and it was like "This really makes sense." When I understood the full impact family dynamics had on individual clients, it became strikingly apparent that I wanted to work with couples and families. I then learned about utilizing the power of an entire family system in conjoint treatment to promote effective outcomes. All of this was so intriguing to me at the age of 26. Additionally, with the permission and blessing of the training clinic director, I and other students were able to utilize our newly gained couples, marriage, and family knowledge within the counselor education clinic. Back in 1971 and 1972 , Drs. Murphy and Goodman were not paid to do provide MFT clinical training as part of their workload. Yet, their dedication to our instruction was clearly evident based upon their willingness to come to our clinic one evening a week, observe our sessions, and provide supervision. They truly believed in us and were willing to invest in our becoming future counselor educators, counseling psychologists, and marriage and family therapists who would effectively train the next generation of practitioners with family therapy educators. The early 1970s was an era when there was expanded interest in several models of individual counseling and psychotherapy. Certainly, there was the very strong influence of Person Centered Therapy in my training. My major advisor at Northern Illinois University, Dr. Robert "Bob" Nejedlo, was one of the last students of Carl Rogers at the University of Wisconsin. While I was greatly influenced by Person-Centered, Phenomenological, and Humanistic Existential approaches, I didn't feel like I had to abandon those theories to also understand and learn about family systems interventions. As I finished my doctorate, I continually thought to myself, "I received the very best of both treatment worlds. I've been trained in individual and group therapy as well as that in family systems." Each type of training helped me feel much better prepared to enter the professional world.

Coll: Knowing that there often are mentoring relationships that strongly impact our professional interests and development, would you mind sharing a little about some of the folks who positively impacted your professional marriage and family interests and development?

Hovestadt: Dr. Robert "Bob" Nejedlo, currently a retired Northern Illinois University professor and a past ACA president, was certainly one of the people I most respected. While his background was Person Centered, he strongly encouraged me to explore other counseling and psychotherapy models. Bob believed there was always more to learn and inspired me to go beyond basic required studies. He provided much personal encouragement and was a tremendous major advisor. He didn't just mentor me to complete my doctorate. He believed his charge was to actively mentor way beyond my graduation. I certainly owe him a huge debt of gratitude for being an excellent role model as an outstanding counselor educator and servant leader in ACES and ACA. According to Bob, mental health professional associations such as ACES, ACA, IAMFC, and AAMFT unified professionals and provided a forum in which we could encourage the appropriate training experiences of future professionals and address the needs of public. It was clear to him, and he made it crystal clear to his students, that once we attained our doctorates we needed to take leadership roles within the professions. I was exceptionally fortunate to have someone like Bob in my life.

Juhnke: In the same way that others positively impacted your professional interests and development, approximately how many doctoral dissertations have you chaired and how has your role as doctoral chair, doctoral committee member, and mentor been rewarding for you?

Hovestadt: That's certainly is one of many excellent reasons doctoral students desire to become faculty in a graduate programs like ours at Western Michigan University and at my former employer Texas A \& M UniversityCommerce. As a faculty member, one gets the opportunity to work with the best and the brightest. It is an incredible opportunity to work with and mentor students who are committed to the profession. Few things compare to watching graduate students develop their research and clinical skills. It is incredible to be a part of these students' lives and 
watch their knowledge base expand. It is so rewarding to see doctoral students grow personally and professionally over the years. Serving doctoral students has been one of the most positive roles that

I have ever experienced. Better yet are that many former students perceive me not just as a mentor but as a friend and a professional colleague. To see my former students contribute in so many ways has been incredibly exciting. They have served as faculty members, department chairs, deans, even vice presidents. Certainly, their participation in national mental health organizations is something that brings a lot of satisfaction to those of us who have had the opportunity ourselves. I have not counted lately but my best estimate is that I have served as a chair for over 50 doctoral students.

Sunich: What words of advice would you have for those seeking to become counselor educators and who wish to specialize in the area of couples, marriage, and family?

Hovestadt: Obviously, there is the necessary path of taking academic coursework. But quite clearly you learn how to be a family therapy educator in part by conducting such therapy with couples and families under supervision. I have seen some excellent people struggle to be effective educators, because they haven't engaged in sufficient clinical practice under supervision. The key to credibility is supervised couples, marriage, and family and child clinical experiences. Without such experience, one can never truly be fully credible. Courses can never account for missing clinical experience. During supervised clinical experiences you can test yourself, you can test models, you can test the theories, and you can experience what works and what doesn't. As counselor educators, we need to be trained in multiple techniques, interventions, strategies, and models of family systems and family therapy. One size does not fit all clinical problems.

Juhnke: Are you engaged in any new leadership roles since you left the AAMFT Presidency?

Hovestadt: I was recently appointed to a 3-year term to serve on the AAMFT Minority Fellowship Program Advisory Committee. I'll also be chairing that committee in 2008 and 2009. On August 30, 2007, the Substance Abuse and Mental Health Services Administration awarded the AAMFT \$650,000 in federal funding through its Minority Fellowship Program. The AAMFT will use the SAMHSA grant funds to support 20 MFT doctoral students in COAMFTE accredited programs in pursuit of training to provide culturally competent mental health and substance abuse treatment to minority/underserved populations. This principal aim is directly related to efforts to reduce health disparities among ethnic minorities in the U.S. by filling a crucial need for mental health service providers.

Coll: You sound very enthused.

Hovestadt: Yes, I am. I believe this will be an excellent opportunity for many and will help insure the continued prominence of the Marriage and Family Profession.

Sunich: Is there anything else we should discuss?

Hovestadt: No, I think that pretty well sums things up for us.

Juhnke: O.K., thank you so very much Alan for taking your time to talk about your experiences as a counselor educator, IAMFC member, and Past AAMFT President.

Hovestadt: Thank you.

Coll: The privilege has been ours. 